\title{
Early Adolescents Parental Relations and Emotional Competence Among Sheik Abduselam Secondary School Students, Jigjiga, Ethiopia
}

\author{
Elmi Muse Haji, Tewodros Demissie Melaku* \\ School of Psychology, College of Education and Behavioural Studies, Jigjiga University, Jigjiga, Ethiopia
}

\section{Email address:}

teddyinish@gmail.com (T. D. Melaku)

${ }^{*}$ Corresponding author

\section{To cite this article:}

Elmi Muse Haji, Tewodros Demissie Melaku. Early Adolescents Parental Relations and Emotional Competence Among Sheik Abduselam Secondary School Students, Jigjiga, Ethiopia. International Journal of Psychological and Brain Sciences. Vol. 5, No. 5, 2020 , pp. 69-74. doi: $10.11648 / j . i j p b s .20200505 .11$

Received: September 4, 2020; Accepted: September 19, 2020; Published: September 28, 2020

\begin{abstract}
Adolescents relation with parents and their overall development has attracted and increasing research attention. And yet identification of parental relationship and adolescents' emotional competence is relatively a new area of research. Given the role emotional competence played in healthy functioning in young adolescents over a life span., it is imperative to study and enhance our understanding of Parent-Early adolescents relationship and emotional competence with different dimensions that compose these constructs. In this context, the main objective of this study was to investigate the correlation between parent-child relationship and emotional competence. 60 Participants (30 boys and 30 girls) with average age of 15.5 were randomly selected from Sheik Abduselam Secondary school, Jigjgia, Ethiopia. Children were provided Parent-child relationship then Emotional competency scales. Analyses were conducted using descriptive statistics-mean \& standard deviations and p-value of Parent-child (boys and Girls) relationship in ten dimensions, emotional competence in five dimensions and Pearson's product moment correlations were employed to identify the association between the Parents-child relationship dimensions with Emotional competence dimensions. Result showed that significant children's perception of their mothers as rewarding (symbolic and Object), loving, and demanding. On the other hand, children did not show any significant differences of their relation with both mothers and fathers in protecting, Object-reward and Indifferent dimensions. However, Children's Perception of their father as Rejecting, Symbolic-Punishment and neglect have significantly different from their mothers. In relation to Emotional Competence, result found out children had average in emotional competency in all dimensions. A notable finding in this study was significance positive parent-child relationship and emotional competence. Positive and negative relationships among the eight dimensions of parent-child relationships (Neglecting, rejecting, Symbolic punishment, Protecting, Symbolic Reward, Object Reward, Loving, Indifferent) except "demanding" and "Object Punishment" significantly related with emotional competence dimensions at $\mathrm{p}<0.05$ significant level in the sample were found. The results proved that statistical significance of the relationship between emotional competence and parent child relationships. Implications and suggestions for future research were discussed.
\end{abstract}

Keywords: Early Adolescents, Parental Relations, Emotional Competence

\section{Introduction}

Family members, particularly parents, are the chief architects in shaping the personality of youngsters. The range and the depth of emotions which parents display to their children builds up the psychological interior of their children. [1]. From all the relationship that adolescents experience throughout their life time, relationship with parents is the most significant in the overall development [2]. Clearly, parental relationship is a great source of reference to determining the Personality and psychosocial development of Early adolescents. Parental relationships are subsumed by various factors such as gender stereotypes, socio-cultural contexts and parents own childhood experiences. The 
nuances of reward and punishment; nature of discipline; amount of permissiveness; bonding and interaction in a parent child relationship have been stressed upon the healthy development of the child [3]. Undoubtedly, these patterns do not remain constant and in fact they continuously evolve and change to suit the individual needs of the growing child. Young adolescents may need a relationship with their parents to attend, discipline and participate, whereas adolescent's responsiveness is much better with parents who practice listening, sharing and encouraging personal space [4]. Indeed, emotionally competent early adolescents have high level persistence, self-motivation, the ability to cope with stress and manage strong feelings, and the ability to empathize with and relate to others." Emotionally smart" children are able to focus on the task at hand in school or at work, can get along with peers and adults are able to delay gratification and can "bounce back" quickly after stressful experiences $[5,19]$.

Although emotions are in part biological the means of emotions and appropriateness of emotional expression are socialized. In the early years of life, socialization primarily takes place via interactions within the family, and characteristics of both parents and children may affect the process of emotion socialization. Children and adolescent's perception about parent child relationships were more strongly linked to social and emotional outcomes. Parent child sharing healthy and warm relationships were found to develop social and emotional potentialities and get an advantage of getting parental suggestions, ideas and communication skills and critical sense of security, [6, 18]. The relationship between affective and emotional aspects of parental behavior and the Childs' emotional adjustment is family and culture specific [7, 20, 21]. The emotional competence of the child depends on parental love and affection and depending on the child rearing practices, interactions with them [8].

Emotional competence, which includes the abilities to understand, express, and regulate emotions [9], is influenced by parents with whom early adolescents have significant interactions on a regular basis. Research conducted in Ethiopian adolescents on quality of parent-child communication concluded that parent-adolescent relation is linked with children's overall wellbeing [10]. However, the study merely concentrated on open parent child communication and relationship with wellbeing of Ethiopian adolescents; however, the overall parent child relationship remains the most reliable predictor of individual differences in psychological, social, and cognitive adjustment in children. Researchers found out Parent-child communication, parental monitoring/engagement, parenting styles and positive feedback from parents have been linked to better social and emotional functioning of adolescents. [11, 12]. However, identification of parenting-child relationship and children emotional competence is relatively a new area of research. Specifically, there are few researches has found on parent-adolescents relationship and Emotional competence conducted in Ethiopia. This research fills the gap of knowledge on status of parent-child relationship and relation with emotional competence on children. Therefore, the overall question of interest in this study was how Emotional Competence relates to Parent-child Relationship.

\section{Objectives}

This study attempted to focus on "Early Adolescents Parental Relations and emotional competence among Sheik Abduselam Secondary School students, Jigjiga, Ethiopia" with the following objectives:

1) To identify the significance difference between adolescents-mother and adolescents-father relationship in different dimensions

2) To determine Emotional Competence level among Early Adolescents

3) To determine the correlation between Early adolescents' parental relation and Emotional competence.

\section{Methods}

\subsection{Participants}

This study is confined to the target population of Sixhundreds Grade Nine Secondary School who were enrolled in 2019/20 academic year at Sheik Abduselam Secondary School, Jigjiga, Ethiopia. Researches would recommend taking $10 \%$ of the population as a sample if there was large population. [13]. Hence, a group of 60 students (30 boys and 30 girls) aged between 13-16 with a mean age of 15.5 and S.D of 2.4 were randomly selected from Grade Nine Secondary School Students, Jigjiga, Ethiopia to serve as participants in this study. Correlational research design was also employed because the study attempts to examine the relationship between Early Parent relationship and emotional competence among samples.

\subsection{Instruments}

The data were collected using Parent-Child Relationship and Emotional Competence scales

a) Parent-child Relationship scale: This scale developed by Nalini Rao [14]

\subsection{Description of the Tool}

The data available on the items of the scale can be grouped into universal dimensions of children's experience of family interaction with the two-parent factor. The tool contained 100 items categorized in to ten dimensions namely, protecting, symbolic punishment, rejecting, object punishment, demanding, indifferent symbolic reward, loving, object reward, and neglecting. Items of the scale are arranged in the same order as the dimensions and they rotate in a cycle through the scale. Each respondent scores the tool for both Father and Mother separately. Items are common for both the parents except for three items, which are different, in the Father and Mother forms due to the nature of variation in 
paternal and maternal relationship with Early adolescents.

b) Emotional Competency Scale:

This tool is based on Likert method, developed by H. C. Sharma and R. Bharadwaj (2007) [15].

\subsection{Description of the Tool}

The scale has 30 items to measure five emotional competencies, where each competency could be measured by six items.

\subsection{Reliability and Validity of Scales}

The Parent-adolescents relationship and emotional competency scales were back and forth -translation into English and Somali was carried out hence to make some adjustments. Then it was administered to fifty students twice over a period of over three to four weeks. The sample consists of 25 boys and 25 girls in the age range of 13-16 studying Grade Nine Jigjiga Model Secondary school
Students.

PCR scale test retest reliability coefficient ranged from 0.70 to 87 for boys sample and 0.77 to 0.87 for girls sample over the ten-sub scales. Similarly, Reliability Coefficient of Emotion Competence Scale was found out 0.76 for both boys and girls.

Face validity for both scales were also established when items was reassigned for scale adaptation and construct validity also checked with the data obtained in other standardized scale

\section{Results and Discussion}

The results of the present study are presented under the following sub-headings as (1) Parent-Child relationship (2) Emotional Competence (3) Association between Parent-child relationship and Emotional competence in the next pages.

Table 1. Early Adolescents perception of father and mother in various dimensions of Parent-child Relationship Scale.

\begin{tabular}{|c|c|c|c|c|c|}
\hline \multirow{2}{*}{ Dimensions } & \multicolumn{2}{|c|}{ Mother } & \multicolumn{2}{|c|}{ Father } & \multirow{2}{*}{ P-value } \\
\hline & M & SD & M & SD & \\
\hline Protecting & 28.60 & $(7.62)$ & 27.96 & $(5.68)$ & 0.123 \\
\hline Object reward & 34.38 & $(6.02$ & 34.18 & $(6.59)$ & 0.08 \\
\hline Love & 30.30 & $(6.02)$ & 45.15 & $(5.99$ & $0.01 *$ \\
\hline Symbolic-Reward & 36.18 & $(6.28)$ & 28.86 & $(6.46)$ & $0.00 *$ \\
\hline Indifferent & 30.70 & $(7.63)$ & 30.73 & $(6.10)$ & 0.53 \\
\hline Demanding & 31.35 & $(7.63)$ & 25.63 & $(8.35)$ & $0.03 *$ \\
\hline Rejecting & 26.36 & $(8.59)$ & 29.06 & $(5.50)$ & $0.00 *$ \\
\hline Symbolic-Punishment & 30.08 & $(6.44)$ & 36.30 & $(6.32)$ & $0.01 *$ \\
\hline
\end{tabular}

Note: $\mathrm{N}=60$.

*Significant at $\mathrm{p}<0.05$.

Table 1 show the mean and standard deviation of scores obtained in various dimensions of PCRS towards mothers and fathers. P-values of the parent-child relationship revealed that significant children's perception of their mothers as rewarding (symbolic and Object), loving, and demanding. On the other hand, children did not show any significant differences of their relation with both mothers and fathers in protecting, Object-reward and Indifferent dimensions. However, Early Adolescents Perception of their father as Rejecting, Symbolic-Punishment and neglect have significantly different from their mothers.

Table 2. Emotional Competencies in various dimensions among samples.

\begin{tabular}{llll}
\hline Emotional Competence Dimension & M & SD & t-score \\
\hline Adequate depth of feeling (ADF) & 51.46 & $(6.93)$ & 50.43 \\
Adequate expression and control of emotions (AFE) & 47.00 & 6.97 & 40.21 \\
Ability to function with emotions (AFE) & 46.26 & 4.23 & 41.03 \\
Ability to cope with problem emotions (ACPE) & 48.98 & 5.85 & 43.00 \\
Encouragement of positive emotions (EPE) & 50.96 & 8.34 & 48.23 \\
\hline
\end{tabular}

Note: $\mathrm{N}=60$.

According to the norms in Emotional competence scale developed by Bharadwaj R \& Sharma H. (2007) Table 2 revealed children have average in emotional competency in all dimensions.

Table 3. Early Adolescents Relationship and Emotional Competence in various dimensions among Sample.

\begin{tabular}{|c|c|c|c|c|c|c|c|c|c|c|c|}
\hline \multicolumn{2}{|c|}{$\begin{array}{l}\text { EC/parent-child } \\
\text { Relationship }\end{array}$} & \multirow{2}{*}{$\begin{array}{l}\text { Mother- } \\
\text { NE } \\
.360^{*}\end{array}$} & \multirow{2}{*}{$\begin{array}{l}\text { Mother- } \\
\text { OR } \\
.057\end{array}$} & \multirow{2}{*}{$\begin{array}{l}\text { Mother- } \\
\text { LV } \\
.090\end{array}$} & \multirow{2}{*}{$\begin{array}{l}\text { Mother- } \\
\text { SR } \\
.039\end{array}$} & \multirow{2}{*}{$\begin{array}{l}\text { Mother- } \\
\text { IN } \\
.118\end{array}$} & \multirow{2}{*}{$\begin{array}{l}\text { Mother- } \\
\text { DE }\end{array}$} & \multirow{2}{*}{$\begin{array}{l}\text { Mother- } \\
\text { OP } \\
.229\end{array}$} & \multirow{2}{*}{$\begin{array}{l}\text { Mother- } \\
\text { RE } \\
.254^{*}\end{array}$} & \multirow{2}{*}{$\begin{array}{l}\text { Mother- } \\
\text { SP } \\
.334^{*}\end{array}$} & \multirow{2}{*}{$\begin{array}{l}\text { Mother- } \\
\text { PRO } \\
.058\end{array}$} \\
\hline & $\mathrm{r}$ & & & & & & & & & & \\
\hline $\mathrm{ADF}$ & Sig(2-tailed) & .005 & .665 & .459 & .768 & .368 & .149 & .078 & .050 & .009 & .658 \\
\hline $\mathrm{AEC}$ & $\mathrm{r}$ & -.082 & $.256^{*}$ & .125 & .161 & -.067 & .141 & -.164 & -.166 & -.143 & .057 \\
\hline
\end{tabular}




\begin{tabular}{|c|c|c|c|c|c|c|c|c|c|c|c|}
\hline \multicolumn{2}{|c|}{$\begin{array}{l}\text { EC/parent-child } \\
\text { Relationship }\end{array}$} & \multirow{2}{*}{$\begin{array}{l}\text { Mother- } \\
\text { NE } \\
.536\end{array}$} & \multirow{2}{*}{$\begin{array}{l}\text { Mother- } \\
\text { OR } \\
.048\end{array}$} & \multirow{2}{*}{$\begin{array}{l}\text { Mother- } \\
\text { LV } \\
.341\end{array}$} & \multirow{2}{*}{$\begin{array}{l}\text { Mother- } \\
\text { SR } \\
.219\end{array}$} & \multirow{2}{*}{$\begin{array}{l}\text { Mother- } \\
\text { IN } \\
.610 *\end{array}$} & \multirow{2}{*}{$\begin{array}{l}\text { Mother- } \\
\text { DE } \\
.28\end{array}$} & \multirow{2}{*}{$\begin{array}{l}\text { Mother- } \\
\text { OP } \\
.209\end{array}$} & \multirow{2}{*}{$\begin{array}{l}\text { Mother- } \\
\text { RE }\end{array}$} & \multirow{2}{*}{$\begin{array}{l}\text { Mother- } \\
\text { SP } \\
.275\end{array}$} & \multirow{2}{*}{$\begin{array}{l}\text { Mother- } \\
\text { PRO }\end{array}$} \\
\hline & Sig(2-tailed) & & & & & & & & & & \\
\hline \multirow{2}{*}{ AFE } & $\mathrm{r}$ & -.102 & .086 & .059 & -.011 & -.056 & -.099 & -.074 & -.077 & -.052 & -.034 \\
\hline & Sig(2-tailed) & .436 & .511 & .656 & .933 & .673 & .454 & .575 & .558 & .695 & .796 \\
\hline \multirow{2}{*}{ ACPE } & $\mathrm{R}$ & -.082 & $.318^{*}$ & .234 & $.352 *$ & -.060 & .178 & .050 & -.031 & .116 & $.268^{*}$ \\
\hline & Sig(2-tailed) & .535 & .013 & .071 & .006 & .649 & .174 & .702 & .817 & .378 & .038 \\
\hline EPE & $\mathrm{R}$ & -.252 & $.411 *$ & $.351 *$ & .248 & -.083 & .020 & -.180 & $-.309 *$ & -.118 & $.288^{*}$ \\
\hline
\end{tabular}

Table 3. Continued.

\begin{tabular}{|c|c|c|c|c|c|c|c|c|c|c|c|}
\hline \multicolumn{2}{|c|}{$\begin{array}{l}\text { EC/parent-child } \\
\text { Relationship }\end{array}$} & \multirow{2}{*}{$\begin{array}{l}\text { Father- } \\
\text { NE } \\
.238\end{array}$} & \multirow{2}{*}{$\begin{array}{l}\text { Father- } \\
\text { OR } \\
.67\end{array}$} & \multirow{2}{*}{$\begin{array}{l}\text { Father- } \\
\text { LV } \\
-.013\end{array}$} & \multirow{2}{*}{$\begin{array}{l}\text { Father- } \\
\text { SR } \\
-.046\end{array}$} & \multirow{2}{*}{$\begin{array}{l}\text { Father- } \\
\text { IN } \\
-.019\end{array}$} & \multirow{2}{*}{$\begin{array}{l}\text { Father- } \\
\text { DE } \\
.45\end{array}$} & \multirow{2}{*}{$\begin{array}{l}\text { Father- } \\
\text { OP } \\
.073\end{array}$} & \multirow{2}{*}{$\begin{array}{l}\text { Father- } \\
\text { RE } \\
.201\end{array}$} & \multirow{2}{*}{$\begin{array}{l}\text { Father- } \\
\text { SP } \\
.115\end{array}$} & \multirow{2}{*}{$\begin{array}{l}\text { Father- } \\
\text { PRO } \\
-.076\end{array}$} \\
\hline$A D F$ & $\mathrm{r}$ & & & & & & & & & & \\
\hline ADF & Sig(2-tailed) & .067 & .611 & .921 & .921 & .883 & .735 & .578 & .124 & .381 & .566 \\
\hline \multirow{2}{*}{$\mathrm{AEC}$} & $\mathrm{r}$ & -.229 & .222 & .074 & .038 & -.089 & .026 & -.103 & -.091 & -.183 & -.050 \\
\hline & Sig(2-tailed) & .079 & .089 & .573 & .773 & .497 & .845 & .435 & .489 & .162 & .705 \\
\hline \multirow{2}{*}{ AFE } & r & -.136 & .161 & -.104 & -.017 & -.104 & -.145 & -.134 & -.013 & -.150 & .046 \\
\hline & Sig(2-tailed) & .301 & .218 & .430 & .895 & $.431 *$ & .269 & .309 & .922 & .252 & .725 \\
\hline ACPE & Sig(2-tailed) & .407 & .092 & .306 & .382 & .391 & .180 & .677 & .757 & .811 & .38 \\
\hline \multirow{2}{*}{ EPE } & $\mathrm{R}$ & -.253 & $.366^{*}$ & $.391 *$ & .219 & -.038 & -.028 & -.219 & -.276 & -.043 & $.402 *$ \\
\hline & Sig(2-tailed) & .051 & .004 & .002 & .092 & .774 & .831 & .093 & .003 & .744 & .001 \\
\hline
\end{tabular}

The results from the table 3 exhibited that there exist significant correlations at $\mathrm{p}<0.05$ significant levels, in the various combinations of the dimensions of the parent Child relationships and the five categories of the emotional competence among sample.

Result in Table 3 revealed that Mother neglecting and mother symbolic punishment significantly correlated with lack of depth of feelings of emotional dimension at $\mathrm{p}<0.05$. Similarly, Mother rejecting significantly correlated with lack of depth of feeling at $p<0.05$ of them father love, father symbolic reward and lack of independent showed negative correlation.

It was also found out mother object reward significantly correlated with adequate Expression of emotions at $\mathrm{p}<0.05$ level and mother neglecting, lack of independent, object punishment, rejecting symbolic punishment and father lack of independence, father object punishment, father rewarding father symbolic punishment, and father protecting negatively correlated.

From table 3, it can be also observed that mother objectreward and mother protecting significantly correlated with ability to cope with problem emotions, father neglecting, father object punishment, father symbolic reward, mother protecting, mother neglecting, mother symbolic punishment, mother rejecting, mother object punishment, mother demanding, mother symbolic reward, mother loving and mother object reward correlated with social maladjustment at $\mathrm{p}<0.05$, father protecting, father symbolic reward, mother protecting, mother symbolic reward, mother loving and mother object reward showed negative correlations. Father loving, father object reward showed negative correlations with social maladjustment at $\mathrm{p}<0.05$.

Father neglecting, father symbolic punishment, father rejecting, father object punishment, father demanding, father symbolic reward, mother protecting, mother neglecting, mother rejecting, mother object punishment, mother demanding, mother symbolic reward, and mother loving significantly correlated with personal disintegration at $\mathrm{p}<0.05$, and of them, father symbolic reward, mother protecting, mother symbolic reward and mother loving showed negative correlations. Father protecting, father loving, father object reward, mother symbolic punishment, and mother object reward correlated with personal disintegration at $\mathrm{p}<0.05$, and of them, father protecting, father loving, father object reward, and mother object reward showed negative correlations.

Table 3 also showed Father protecting, father neglecting, father object punishment, father symbolic reward, father loving, father object reward, mother protecting, mother neglecting, mother rejecting, mother object punishment, mother symbolic reward, mother loving, and mother object reward significantly correlated with lack of independence at $\mathrm{p}<0.05$, and of them, father protecting, father symbolic reward, father loving, father object reward, mother protecting, mother symbolic reward, mother loving and mother object reward showed negative correlations. Father rejecting, father demanding, mother symbolic punishment, and mother demanding showed positive correlations with lack of independence at $\mathrm{p}<0.05$.

Father protecting, father neglecting, father symbolic punishment, father rejecting, father object punishment, father symbolic reward, father object reward, mother protecting, mother neglecting, mother symbolic punishment, mother rejecting, mother object punishment, mother demanding, mother symbolic reward, mother loving and mother object reward significantly correlated with emotional maturity at $\mathrm{p}<0.05$, and of them, father protecting, father symbolic reward, father object reward, mother protecting, mother symbolic reward, mother loving and mother object reward showed negative correlations. Father demanding showed positive correlation and father loving showed negative correlation with emotional maturity at $\mathrm{p}<0.05$. 
Table 3 also revealed father demanding and object punishment and Mother demanding and object punishment did not show any significant relationship at all with all the five categories of emotional competence.

\section{Discussion}

The present study determined the parent-child relationship and emotional competence on school children in the age range of 13 to 16 years. This research study's findings regarding children's perception of their mothers as rewarding (symbolic and Object), loving, and demanding supports past research. [16]. However, in contrast to present findings Karuna et al., [17] found out that mothers and fathers were almost equally protective, demanding and give equal symbolic rewards and object rewards towards their children.

Building on the past findings, in this research it was found out children did not show any significant differences of their relation with both mothers and fathers in protecting, Objectreward and Indifferent dimensions [16]. This might be both parents are involving in child rearing practices. In addition, this research finding was in consistent with Shaheeda S. et al. 2012 finding which was find out Children's Perception of their father as Rejecting, Symbolic-Punishment and neglect have significantly different from their mothers. This might be the fact that since early adolescents as a developmental period involved with rebellion fathers enforce strict disciplining as compared to mothers.

This finding also observed that early adolescents emotional competence level among the five dimensions was average. Average level of Adequate depth of feeling (ADF) children's' effective judgment and personality integration was average which affects children vigorous participation in living. Average level of Adequate Expression and Control of Emotion (AFE) implies these children had only average level of adequate expression and their control which may be regard as natural dynamic stability of an individual to express and control emotions spontaneously as demanded by the situation. In addition to that children's average level of Ability to function with emotions (AFE), Ability to cope with problem emotions (ACPE) and Encouragement of positive emotions (EPE) implies that children found on average level in skills consisting of the ability to understand, manage and express the social and emotional aspects of one's life in ways that enable the successful management of life [20]

Based on the findings of the two parent-early adolescents relationship and emotional competence measures and the correlation analysis of between parent-child relationship and emotional competence was found out that parent-child relationship dimensions of there are both positive and negative relationships among the eight dimensions of parent-child relationships (Neglecting, rejecting, Symbolic punishment, Protecting, Symbolic Reward, Object Reward, Loving, Indifferent) except "demanding" and "Object Punishment" significantly related with emotional competence dimensions except with 'ability to function with emotions at $p<0.05$ significant level in the sample. The results proved that statistical significance of the relationship between emotional competence and the parent child relationships. This research fining builds the past research on Parent-Child Relationship and Emotional Competence on children. According to Devi U. et. al [8] conducted a study on "Relationship between Adolescents Perception about Family Environment and Emotional Intelligence". 224 adolescents studying intermediate course constituted the sample. Results revealed the four out of eight dimensions of family environment, cohesion, expressiveness, acceptance and caring and active recreational orientation were positively and significantly related to total emotional intelligence of adolescents

\section{Conclusion, Limitations \& Recommendations}

\subsection{Conclusion}

This study explored parent child relationship and Emotional competence among youngsters, and often times over looked, school settings. The result showed that significant children's perception of their mothers as rewarding (symbolic and Object), loving, and demanding. On the other hand, children did not show any significant differences of their relation with both mothers and fathers in protecting, Object-reward and Indifferent dimensions. However, Children's Perception of their father as Rejecting, Symbolic-Punishment and neglect have significantly different from their mothers. The study has also addressed the level of emotion competence among samples and it was found that majority students had average emotional competence level in various dimensions. The current study also presented a look into the relationship between parent-child relationship and emotional competence, from which a conclusion can be drawn that the emotion competence was significantly correlated to parent-child relationships in the sample except "demanding" and Object-punishment".

\subsection{Limitations of the Study}

One of the limitations of this study is the sample size. There are only 30 girls and 30 boys' participants in the current study. A larger sample would be needed for power to generalize to a wider population. Another limitation is that the sample students were from schools, which are mostly lower-income family. This study did not address diverse socioeconomic status of students' family. Lastly, the design and analysis strategies are correlation in nature. Therefore, issues of causality cannot be inferred within the present study.

\subsection{Recommendations}

1) Since maintaining close relationship with early adolescents is a very demanding endeavor parents need to focus on fostering their relation with their children's 
which ensures quality relationship in turn determining the Personality and psychosocial development of children. To that end, Psychologists should provide training parents (i.e. mother and fathers) about parentchild relationship and its impact on the child's overall development.

2) The study would warrant further evaluation of poor nature of the emotional competence of the sample. The implication would be to refer them for more screening of emotional disturbances and parent training on emotional competence appears imperative, to enhance their relationships with their children, thereby improving the emotional competence of the sample.

\section{Declaration}

The authors declare that there is no any competing interest.

\section{Acknowledgements}

The authors express gratitude to the all the respondents in this study for their cooperation and also duly acknowledge Sheik Abduselam Secondary School Directors.

\section{References}

[1] Lamb, M. E., \& Lewis, C. (2005): The role of parent-child relationships in child development. In M. H. Bornstein \& M. E. Lamb (Eds.), Developmental science: An advanced textbook (Fifth edition; pp. 429-468). Mahwah, NJ: Lawrence Erlbaum Associates.

[2] Morris AS, Silk JS, Steinberg L, Myers SS, Robinson (2007). The Role of the Family Context in the Development of Emotion Regulation. LR Soc Dev. 2007 May 1; 16 (2): 361388 .

[3] Naghavi. F., Redzuan M. (2012). Relationship between family functioning, alexithymia, and emotional intelligence among early adolescents in Tehran-Iran. Life Sci. J. 9 396-401.

[4] Boutelle, K., Eisenberg, M. E., Gregory, M. L., \& NeumarkSztainer, D. (2009). The reciprocal relationship between parent-child connectedness and adolescent emotional functioning over 5 years. Journal of Psychosomatic Research, 66 , 309-316.

http://dx.doi.org/10.1016/j.jpsychores.2008.10.019

[5] Hawley, T. (2000). Starting Smart: How Early Experiences Affect Brain Development.

[6] Clayton, C. L. (2014). 'With my parents I can tell them anything': Intimacy levels within British Chinese families. International Journal of Adolescence and Youth, 19, 22-36.

[7] Nihara K., Tamiyasu \& Yoshikazo O. (1987). Homes of TMR children: Comparison between American \& Japanese families. American Journal of Mental Deficiency, 91, 486-495.
[8] Uma D. \& Rayal, U. (2004) Adolescent 's Perception about family environment \& emotional intelligence. Indian Psychological Review, 62, 3, 157-167.

[9] Denham S. (1998). The Guilford series on Special and emotional development. Emotional development in young children. Guilford Press Bhardwaj R. \& Sharma H. (2007). Manual for the Scale of Emotional Competencies Agra: National Psychological Corporation.

[10] Bireda A. \& Pillay J. (2017): Perceived parent-child communication and well-being among Ethiopian adolescents, International Journal of Adolescence and Youth, DOI: $10.1080 / 02673843.2017 .1299016$.

[11] Dishion T. \& McMahon R. (1998). Parental monitoring and the prevention of child and adolescent problem behavior: A conceptual and empirical formulation Clin Child Fam Psychol Rev, pp. 61-7.

[12] Brody G., Brown A, \& Kernis M., (2000). Fragile self-esteem in children and its associations with perceived patterns of parent-child communication Pers, 68 (2000), pp. 225-252.

[13] Sudman, S. (1976) Applied Sampling. New York: Academic Press.

[14] Rao N. (2007). Parent Child Relationship Scale. Agra: National Psychological Corporation. http://psychology.jrank.org/pages/472/Parent-ChildRelationships.

[15] Bhardwaj R. \& Sharma H. (2007). Manual for the Scale of Emotional Competencies Agra: National Psychological Corporation.

[16] Shaheeda S. \& Nadhia H. (2012) A Comparative Study on Adolescent-Parent Relationship among Boys and Girls in a Rural Setting, Studies on Home and Community Science, 6: 2, 121-125, DOI: 10.1080/09737189.2012.11885377.

[17] Karuna S., \& Shubha D. (2015): Examining Parent Child Relationship of Adolescents Girls at Jaipur City; Rajasthan (India), International Journal of Multidisciplinary Research and Development, Vol: 2, Issue 10.

[18] Denham S. \& Anita T. (2002) Parental Contributions to Preschoolers' Understanding of Emotion, Marriage \& Family Review, 34: 3-4, 311 343, DOI: 10.1300/J002v34n03_06.

[19] Izard E. (2001). Emotional intelligence or adaptive emotions? Emotion, 1 (3), 249-257. https://doi.org/10.1037/15283542.1.3.249.

[20] Saarni, C., \& Weber, H. (1999). Emotional displays and dissemblance in childhood: Implications for self-presentation. In P. Philippot, R. S. Feldman, \& E. Coats (Eds.), The social context of nonverbal behavior (pp. 71-105). Cambridge, UK: Cambridge University Pres.

[21] Waylen, A., Stallard, N., \& Stewart-Brown, S. (2008). Parenting and health in mid-childhood: A longitudinal study. The European Journal of Public Health, 18, 300-305. 